\title{
Proliferative and Degenerative Changes in Striatal Spiny Neurons in Huntington's Disease: A Combined Study Using the Section-Golgi Method and Calbindin D28k Immunocytochemistry
}

\author{
Robert J. Ferrante, ${ }^{1,3}$ Neil W. Kowall, ${ }^{2,3}$ and Edward P. Richardson, Jr. ${ }^{1,3}$ \\ ${ }^{1}$ C. S. Kubik Laboratory for Neuropathology, James Homer Wright Pathology Laboratories, ${ }^{2}$ Neurology Service, \\ Massachusetts General Hospital, and the ${ }^{3}$ Department of Neurology-Neuropathology, Harvard Medical School, Boston, \\ Massachusetts 02114
}

\begin{abstract}
Dysmorphic alterations of dendritic arbors and spines in spiny striatal neurons were identified in section-Golgi impregnations of moderate and severe grades of Huntington's disease (HD). These alterations could be characterized as either proliferative or degenerative changes. Proliferative changes included prominent recurving of distal dendritic segments, short-segment branching along dendrites, and increased numbers and size of dendritic spines. Degenerative alterations consisted of truncated dendritic arborizations, occasional focal dendritic swellings, and marked spine loss. Proliferative changes were found primarily in moderate grades of HD, while degenerative changes were predominantly found in severe grades. Cytopathologic changes increased with neuropathologic severity. Similar morphologic alterations were observed in calbindin D28K (Calb) stained neurons in HD striatum. The immunoreactive intensity of Calb staining was increased in the distal dendrites of positive neurons in HD striatum. The present findings provide morphologic and quantitative evidence that confirms an early and marked involvement of spiny striatal neurons in HD and suggest that neuronal growth, rather than degeneration, may be the harbinger of cell death in this disorder.
\end{abstract}

Huntington's disease (HD) is a neurodegenerative disorder characterized by progressive choreiform movements and dementia (Martin and Gusella, 1986). The major neuropathologic abnormalities are found within the neostriatum (Vonsattel et al., 1985). There is gross atrophy of both the caudate nucleus and putamen accompanied by marked neuronal loss and astrogliosis. Five grades of severity (grade 0 to grade 4 ) can be defined according to the degree of neuropathologic involvement, with grade 4 representing the most severe (Vonsattel et al., 1985).

Neuronal populations of the neostriatum can be classified with respect to their cytoarchitectural features and neurochemical content (Fox et al., 1971; Graybiel and Ragsdale, 1983; Graveland et al., 1985a; Kowall et al., 1987b). One basis for classification is the relative presence or absence of dendritic

\footnotetext{
Received Apr. 3, 1991; revised July 2, 1991; accepted July 17, 1991.

We thank Dr. Charles Gerfen for his generous gift of antisera against calbindin D28k, Dr. M. Flint Beal for reviewing the manuscript, and Lawrence Cherkas for photographic assistance. This work was supported by NIH Grant NS25588-04.

Correspondence should be addressed to Robert J. Ferrante, Pathology Department, Neuropathology Laboratory, Massachusetts General Hospital, Warren 333B, Boston, MA 02114.

Copyright (C) 1991 Society for Neuroscience $0270-6474 / 91 / 113877-11 \$ 05.00 / 0$
}

spines, as identified in Golgi preparations; the cell types so demonstrated are termed spiny and aspiny striatal neurons (Graveland et al., 1985a). Biochemical characterization further distinguishes these neuronal subtypes. Enzyme- and immunohistochemical methods demonstrate that striatal neurons contain specific neurochemical substances and related enzymes. Aspiny neurons contain somatostatin (Ferrante et al., 1987a; Kowall et al., 1987b), neuropeptide Y (Dawbarn et al., 1985; Ferrante et al., 1987a), NADPH-diaphorase (Ferrante et al., 1987a; Kowall et al., 1987b), AChE (Parent et al., 1984; Ferrante et al., 1987b), ChAT (Levey et al., 1983; Ferrante et al., 1987c), vasoactive intestinal polypeptide (Theriault et al., 1987), and cholecystokinin (Takagi et al., 1984), while spiny neurons contain GABA (Ribak et al., 1979), substance P (Izzo et al., 1987), enkephalin (Izzo et al., 1987), dynorphin (Besson et al., 1990), transforming growth factor $\alpha$ (Fallon, 1987), and calbindin D28k (Calb) (Gerfen et al., 1985; DiFiglia et al., 1989; Celio, 1990).

Although routine histologic methods do not clearly reveal any specific cellular susceptibility, other methods show that there is a selective pattern of neuronal degeneration within the striatum in HD (Kowall et al., 1987a). Medium-sized, spiny projection neurons, and the neurochemical markers contained within them, are disproportionately affected early and most severely in the disease (Graveland et al., 1985b; Ferrante et al., 1986; Kowall et al., 1987a; Seto-Ohshima et al., 1988; Goto et al., 1989), while large and medium-sized aspiny interneurons are relatively spared (Dawbarn et al., 1985; Ferrante et al., 1985, 1987a,b,d). It has recently been suggested that there may also be a differential vulnerability among spiny striatal neurons in HD on the basis of immunohistochemical staining of enkephalin- and substance $\mathrm{P}$-positive axon terminals in the globus pallidus and substantia nigra (Reiner et al., 1988). While previous studies have demonstrated quantitative reductions in immunoreactive subsets of striatal spiny neurons in HD (Seto-Ohshima et al., 1988; Goto et al., 1989; Kiyama et al., 1990), dysmorphic changes have not been previously demonstrated in any neurochemically defined neuronal subpopulation in this disorder.

Calb, a $28 \mathrm{kDa}$ protein occurring in high concentration in the mammalian brain, has been found to be localized to mediumsized spiny neurons and to axon terminals within the striatal matrix compartment (Gerfen et al., 1985; Celio, 1990). It has been suggested that Calb may function as a cellular calcium buffer (Heizmann, 1984). If increased neuronal calcium plays a role in excitotoxic cell death (Collins, 1987), those neuronal subtypes that have the capacity to buffer intracellular calcium 
may be less affected (Nitsch et al., 1989; Slotvier, 1989; Yamada et al., 1990).

Using both single-section Golgi preparations and immunocytochemistry for Calb, we studied spiny striatal neurons in moderate and severe grades of HD. In addition, we examined whether the distribution of Calb is affected by the disease process. The latter study has been reported elsewhere in preliminary form (Ferrante et al., 1988).

\section{Materials and Methods}

Postmortem striatal tissue from 18 patients with morphologically confirmed HD (mean age, 68.9 years; range, 51-92 years) and 15 agematched controls with no evidence of neurologic disease (mean age, 70.8 years; range, $46-89$ years) was dissected fresh and placed in cold $\left(4^{\circ} \mathrm{C}\right) 10 \%$ neutral buffered formalin. The HD cases were of moderate and severe grades (grade $2, n=5$; grade $3, n=8$; grade $4, n=5$ ) (Vonsattel et al., 1985). Postmortem intervals in both HD and control cases did not exceed $12 \mathrm{hr}$. Tissue blocks of the striatum were fixed 24 $48 \mathrm{hr}$ and vibratome sectioned at 50 and $100 \mu \mathrm{m}$. Cut sections were stored in $0.1 \mathrm{M}$ phosphate buffer at $4^{\circ} \mathrm{C}$ for subsequent section-Golgi impregnation and immunocytochemical staining.

Single-section Golgi procedure. The single-section Golgi technique of Gabbott and Somogyi (1984), as modified by Izzo et al. (1987), was carried out on $100 \mu \mathrm{m}$ sections of HD and normal striatum. Sections, no wider than $1 \mathrm{~cm}$ and the full dorsoventral length of the caudate nucleus and putamen, were postfixed in $1 \%$ osmium tetroxide for 15 min and free floated in $3.5 \%$ aqueous solution of potassium dichromate for 1-2 hr, and then each section was placed flat on a microscope slide; after excess potassium dichromate solution was blotted from the edge of the tissue section, each section was "sandwiched" with another microscope slide, and the entire assembly was placed in 1-2\% silver nitrate solution. The development of the chromated section with silver nitrate was assessed by observing the reaction product under the microscope. Optimum time in silver nitrate varied between 1 and $6 \mathrm{hr}$. Sections that remained in silver nitrate overnight $(12-18 \mathrm{hr}$ ) resulted in excess formation of silver chromate crystals, which impaired the visualization of stained neurons. The microscope slides were carefully separated, and the Golgi-impregnated sections were dehydrated, softened with cedar wood oil, and mounted under coverglass.

The spine density of spiny striatal neurons was calculated in sections from controls ( $n=20$ dendrites) and from patients with moderate ( $n$ $=25$ dendrites) and severe grades ( $n=29$ dendrites) of HD by counting the total number of spines divided by the dendritic length, using a $40 \times$ oil immersion lens. Only completely impregnated dendrites found entirely within the tissue section were used for spine counts.

Immunocytochemistry. Immunocytochemistry was performed on 50$\mu \mathrm{m}$-thick striatal sections, using an antiserum against calbindin D28k (Calb). This Calb antiserum, raised in rabbits against calbindin isolated from human cerebellum, has been previously characterized (Baimbridge et al., 1982). Tissue sections were preincubated in absolute methanol, $0.3 \%$ hydrogen peroxide solution for $30 \mathrm{~min}$, washed in three changes of phosphate-buffered saline (PBS; $\mathrm{pH} 7.4$ ) for $10 \mathrm{~min}$ each, placed in $10 \%$ normal goat serum (GIBCO Labs, Grand Island, NY) for $1 \mathrm{hr}$, incubated free floating in primary antiserum at room temperature for $12-18 \mathrm{hr}(1: 1000$ dilution with $0.3 \%$ Triton $\mathrm{X}-100$ and $10 \%$ normal goat serum), washed again in three changes of PBS for $10 \mathrm{~min}$ each, placed in peroxidase-conjugated goat anti-rabbit IgG (1:300 in PBS) (Boehringer Mannheim, Indianapolis, IN), washed in three changes of PBS for $10 \mathrm{~min}$ each, and reacted with 3,3'-diaminobenzidine $\mathrm{HCl}(1$ $\mathrm{mg} / \mathrm{ml}$ ) in Tris- $\mathrm{HCl}$ buffer with $0.005 \%$ hydrogen peroxide. In all cases, silver intensification was performed according to the method of Gallyas et al. (1982).

The number of Calb-positive neurons in control ( $n=54$ areas) and HD ( $n=50$ areas) sections was counted in $1 \mathrm{~mm}^{2}$ areas at the level of the head of the caudate nucleus in both dorsal and ventral striatum. Calb neurons were similarly counted in the medial portion of caudate nucleus just beneath the ependyma, and laterally adjacent to the internal capsule. Neuronal counts were made using a ruled-graticule eyepiece at $250 \times$.

As controls for the specificity of immunostaining for Calb, tissue sections were incubated in PBS or preimmune serum without antibodies directed against Calb. Sections of human cerebellum were processed in conjunction with striatal sections as controls for positive Calb labeling.
All results were analyzed using Student's $t$ test and are expressed as means \pm standard errors.

\section{Results}

\section{Section Golgi}

Single-section Golgi preparations were successful in all cases. There was, however, some variability in the relative quality and density of cellular Golgi staining from case to case. While the principal striatal subclasses of neurons were represented in both HD and control cases, the cells most frequently impregnated were medium-sized, densely spiny neurons (spiny type I). Both large and medium-sized aspiny neurons, aspiny II and aspiny I, respectively, were infrequently encountered and represented no more than $1-2 \%$ of the impregnated neurons in both HD and control cases. There was little difference in the density of neuronal impregnations between controls and the moderate grade (grade 2) of HD. Striatal sections from severe grades (grades 3 and 4) of HD were predominantly characterized by fewer neurons and larger numbers of astrocytes.

In control striatum, neurons were impregnated in their entirety and displayed no alterations induced by postmorten delay (i.e., incomplete impregnation and changes in neuronal morphology; see Morest and Morest, 1966; Williams et al., 1978). The general cytoarchitectural features, including dendritic configurations and branching patterns, were normal. Attention was focused primarily on medium-sized spiny neurons (Fig. 1). Their somal shape was round to oval and occasionally pyramidal. Three to seven primary dendritic arbors originated from the neuronal soma with two to five subsequent bifurcations. These dendritic branches radiated centrifugally in all directions. The dendrites were uniform in width and devoid of any moniliform appearance, and they tapered abruptly to a point at the distal end. Numerous spines of three morphologic types (thin, stubby, and mushroom shaped) (Graveland et al., 1985a) were distributed in a heterogeneous pattern along the course of the dendritic arbors. The primary dendritic segments and the cell soma contained few or no spines, which first appeared with great frequency on the secondary branches. The spine density remained relatively consistent to the distal extent of the dendrites and varied little from neuron to neuron (mean, $7.4 \pm 0.9 / 10$ $\mu \mathrm{m}$; range, $6.4-8.6 / 10 \mu \mathrm{m} ; n=20$ ). Occasional recurving of the terminal segments toward the cell soma was observed in three control cases. These were 66-, 78-, and 89-year-old patients who each died acutely of myocardial infarction.

In comparison to controls, there were striking abnormalities in the morphology of impregnated spiny neurons in HD striatum. The morphologic alterations in these neurons could be subdivided into two categories, those of either a proliferative or a degenerative appearance. The proliferative changes, by their very nature, were associated with a growth process. They included a twisting and recurving of the distal dendritic segment in toward the cell soma, increased number and size of dendritic spines, and alterations in the dendritic branching pattern (Fig. 2). The latter occurred as contorted, short-segment branching along dendritic arbors. Although this new branching could be found along any area of the dendritic length, it was most often observed as two to three branches at the distal end of dendrites (Fig. 2B,E). Numerous, enlarged growth cone-like processes with filopodia were present on the tips of distal dendrites and short-segment branches (Fig. $2 B, E$ ). These structures are characteristic of dendritic growth and were not observed in the normal condition. Dendritic arborizations were often sinuous. Re- 


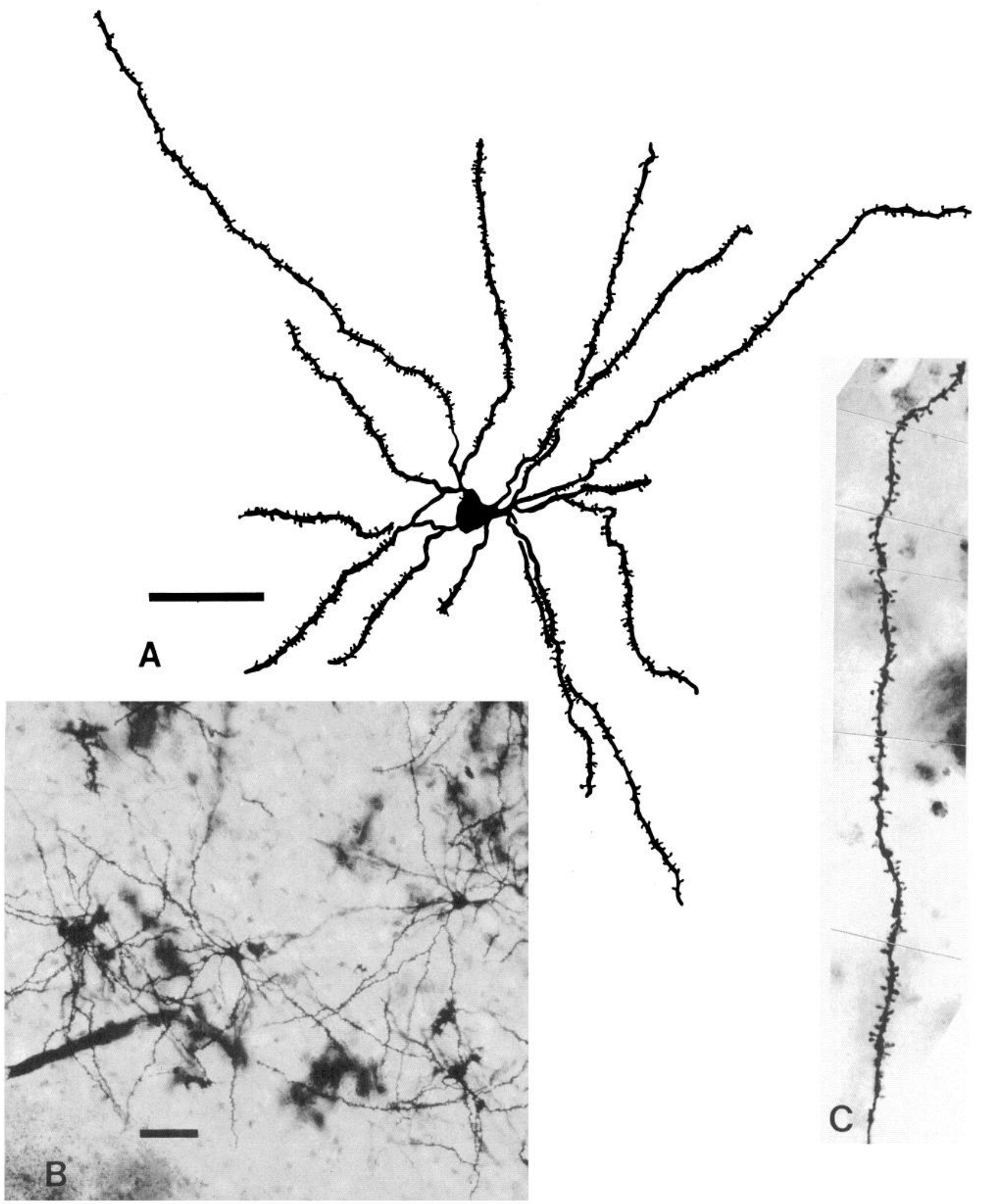

Figure 1. Morphology of medium-sized spiny neurons in normal human striatum. $A$, Camera lucida drawing of a medium-sized spiny neuron (type I) from the caudate nucleus. The cytoarchitectural features include a round to oval somal shape with generally three to seven primary dendritic branches with two to five subsequent bifurcations. $B$, Photomicrograph of a field of medium-sized spiny neurons in the caudate nucleus. Dendritic arbors radiate centrifugally in all directions. $C$, Photomontage of a typical dendritic arbor. Spine density remains relatively consistent throughout the dendritic length. Scale bars in $A$ and $B, 50 \mu \mathrm{m}$. 


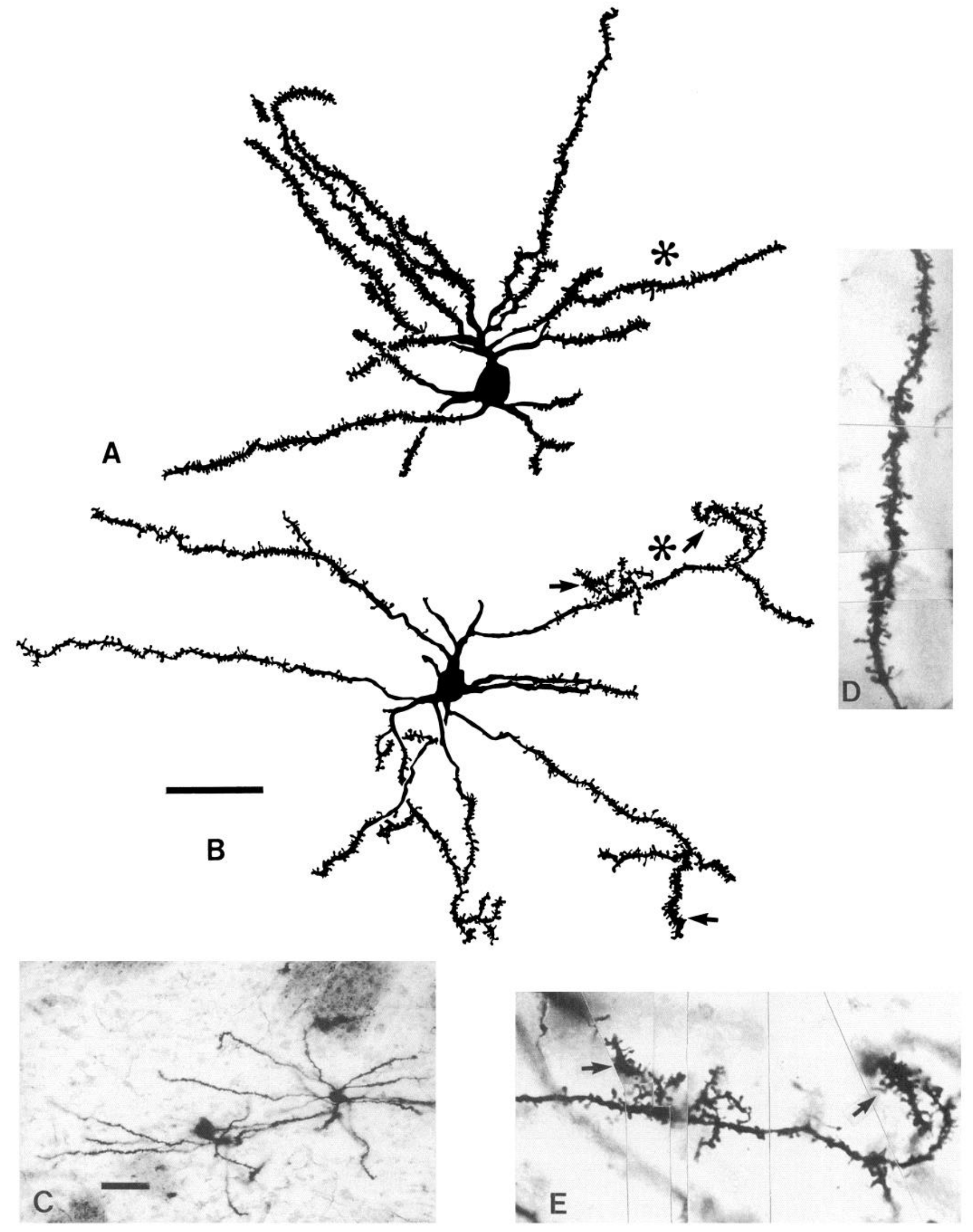


curving of distal dendritic segments was present in at least one arbor of almost all neurons. The most prominent and consistent finding was a significant increase in dendritic spine density (mean, $13.6 \pm 2.1 / 10 \mu \mathrm{m}$; range, $11.7-17.2 / 10 \mu \mathrm{m} ; n=25 ; p<0.001)$, especially along areas of new growth (short-segment branching and distal dendritic segments). Proliferative changes occurred most frequently in the moderate grade (grade 2) of HD. There was, however, a dorsoventral gradient of cytopathologic effect in the moderate grade, with degenerative alterations more prominent in the dorsal extent of the caudate nucleus.

In severe grades of $\mathrm{HD}$, there was considerable variability in dysmorphic neuronal changes observed. Although proliferative and degenerative changes were present, the most frequent were degenerative in nature. Degenerative changes were characterized by truncated dendritic arbors, spinc loss, and irrcgular focal swellings alorg dendrites (Fig. 3). These changes were not a consequence of incomplete impregnation (Williams et al., 1978). The angle of recurving distal dendritic segments was much more acute and tortuous in severe grades. This neuronal alteration increased with the severity of the disorder, such that more recurved distal dendritic segments were observed in severe grades of HD. Most neurons had marked spine loss (mean, $3.1 \pm 0.2 /$ $10 \mu \mathrm{m}$; range, $2.8-3.6 / 10 \mu \mathrm{m} ; n=29 ; p<0.01$ ). Many fibrous astrocytes were present within the sections.

Although the relative number of impregnated aspiny neurons in control and HD striatum was small, no dysmorphic changes were identified in them. Sparsely spiny striatal neurons were equally few in number and observed only in controls and the moderate grade of HD. No qualitative changes in this neuronal subtype, however, could be ascertained.

\section{Calbindin D28k}

Calb in the striatum was localized to medium-sized neurons evenly distributed throughout the caudate nucleus and putamen. These neurons and immunoreactive axon terminals within the neuropil were primarily confined to the striatal matrix zone, with the patch compartments devoid of intense terminal immunoreactivity and positive cells (Fig. 4). While immunostaining delineated the entire neuron, the greater intensity of immunoreactivity was proximal. That is, the neuronal soma and primary and secondary dendritic arbors were more intensely stained, while terminal-order branching was less intensely immunopositive (Fig. 5A).

In severe grades of $\mathrm{HD}$, the number of Calb neurons was significantly decreased within the striatum (HD, $62 \pm 7 / \mathrm{mm}^{2}$, $n=50$; control, $152 \pm 9 / \mathrm{mm}^{2}, n=54 ; p<0.001$ ) (Fig. 6). There was a dorsoventral gradient of Calb-positive neuronal loss. In the caudate nucleus, there was proportionately greater loss of neurons in the medial and superior parts (HD: dorsomedial, $43.8 \pm 5, n=34$; ventromedial, $61.3 \pm 6, n=32$ dorsolateral, $61.3 \pm 8, n=34$; ventrolateral, $79.3 \pm 4, n=32$; control: dorsomedial, $154.3 \pm 13, n=9$; ventromedial, 155.5 $\pm 8, n=9$; dorsolateral, $149.8 \pm 6, n=9$; ventrolateral, 153.8 $\pm 7, n=9$ ). The patch-matrix pattern was faint in all sections, being most obvious in the nucleus accumbens and entirely indistinct in the dorsal striatum. Dysmorphic changes were present in most Calb-positive neurons in HD striatum. These alterations were qualitatively similar to the entire range of cytopathologic changes observed in Golgi impregnations of the same cases (Fig. 7). The pattern of dendritic branching was tortuous, with marked recurving of distal arbors. Terminal segment branching and clubbing of distal dendritic ends was common. Both quantitative and qualitative alterations of dendritic spines were observed. In contrast to what was seen in control neurons, there was a distal dendritic shift of immunoreactive intensity in Calb-positive striatal neurons in HD. Calb immunoreactivity was moderately intense within the cell soma and less intense in the primary and sccondary dendrites. The most distal arbors were intensely immunoreactive, appearing almost black (Fig. 5B).

\section{Discussion}

The present report confirms and extends the previous observation that in HD there are marked alterations in the neuronal morphology of spiny striatal neurons. While this study is in agreement with previously reported Golgi observations in HD (Graveland et al., 1985b), the present findings emphasize the progressive nature of the disorder. Dysmorphic changes in spiny neurons in the striatum of the moderate grade of HD are primarily proliferative. This phase is characterized by a new growth in the neuron, as demonstrated by increased dendritic spine density and size, short-segment branching along dendritic arbors, and recurving of the distal dendritic segments. By comparison, ncuronal changes in scverc grades arc almost cntirely degenerative. There is a significant loss of dendritic spines along varicose and truncated dendrites.

Proliferative changes, using Golgi preparations, have been described in other neuropathologic conditions (DeLorenzo and Glaser, 1989). They are reminiscent of the dendritic growth and differentiation observed in immature neurons (Morest, 1969). Three control striata of older patients in this study contained a small number of spiny neurons with recurving dendritic distal segments. This is consistent with other reports and is described as a function of age (Buell and Coleman, 1979; Graveland et al., 1985b).

Golgi techniques have been employed in a variety of studies of cellular neuropathology since the last quarter of the 19th century (for review, see Williams et al., 1978). Because they detail the cell in its entirety, they are most useful in identifying morphologic alterations as well as complementing immunocytochemical (Izzo et al., 1987) and ultrastructural studies (Williams et al., 1977). In any attempt to identify abnormalities of neuronal architecture using Golgi procedures, it is necessary to distinguish alterations associated with the autolytic process from those occurring as a consequence of the disease (Morest and Morest, 1966; Williams et al., 1978). The former, in fact, may

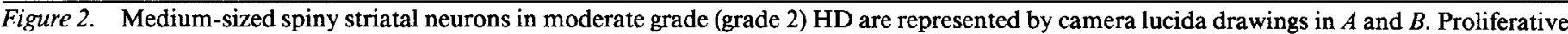

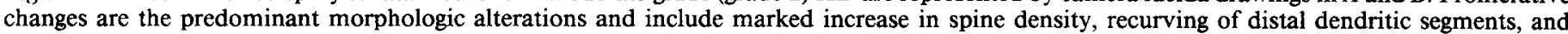

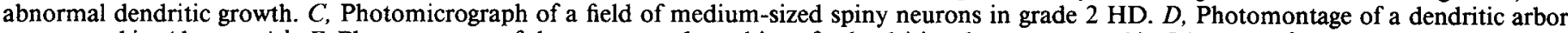

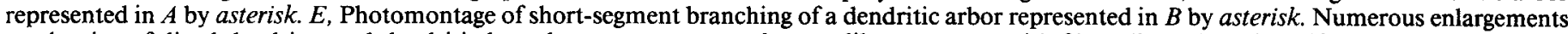

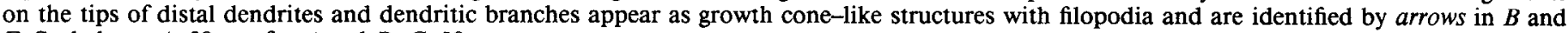
$E$. Scale bars: $A, 50 \mu \mathrm{m}$ for $A$ and $B ; C, 50 \mu \mathrm{m}$. 

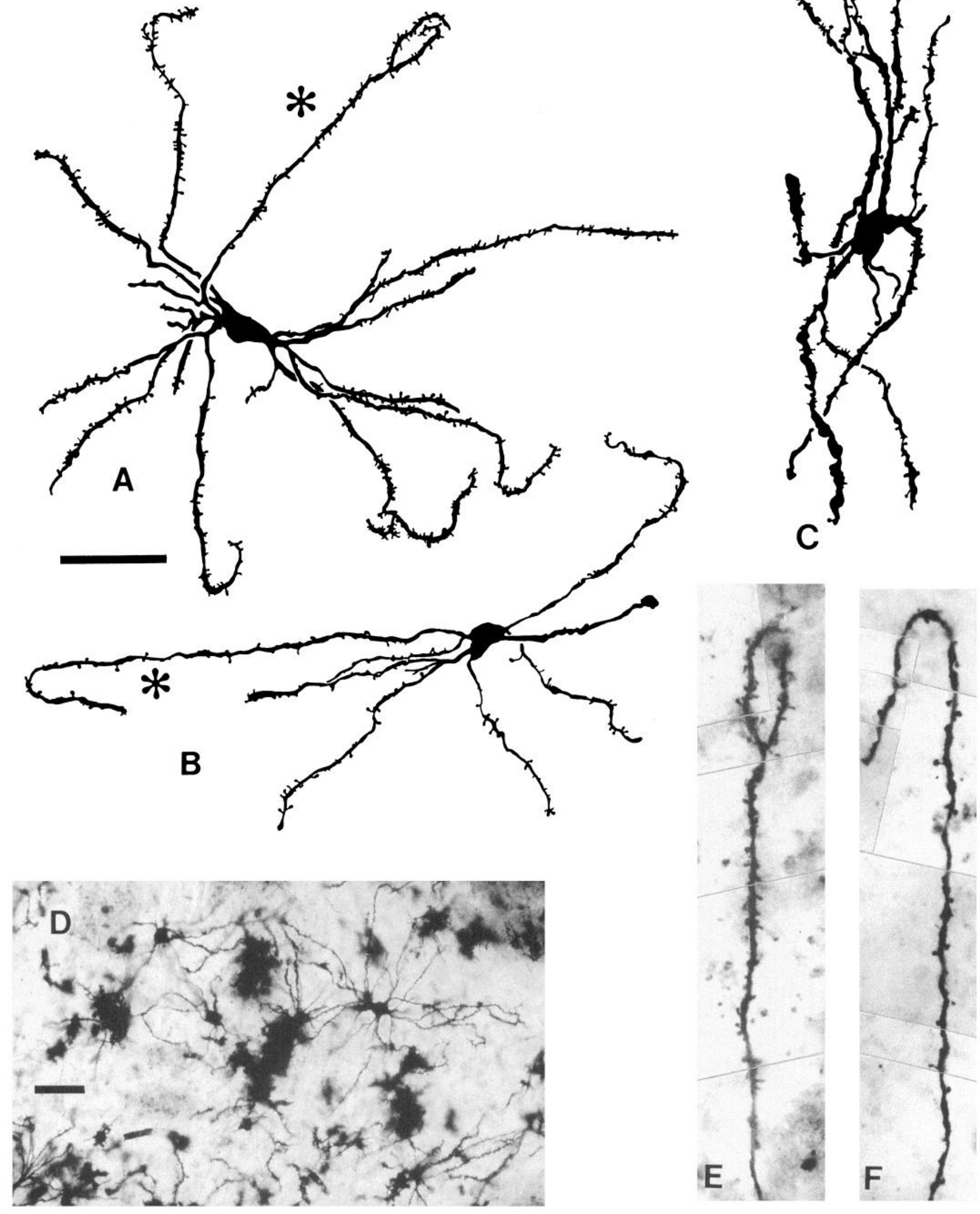

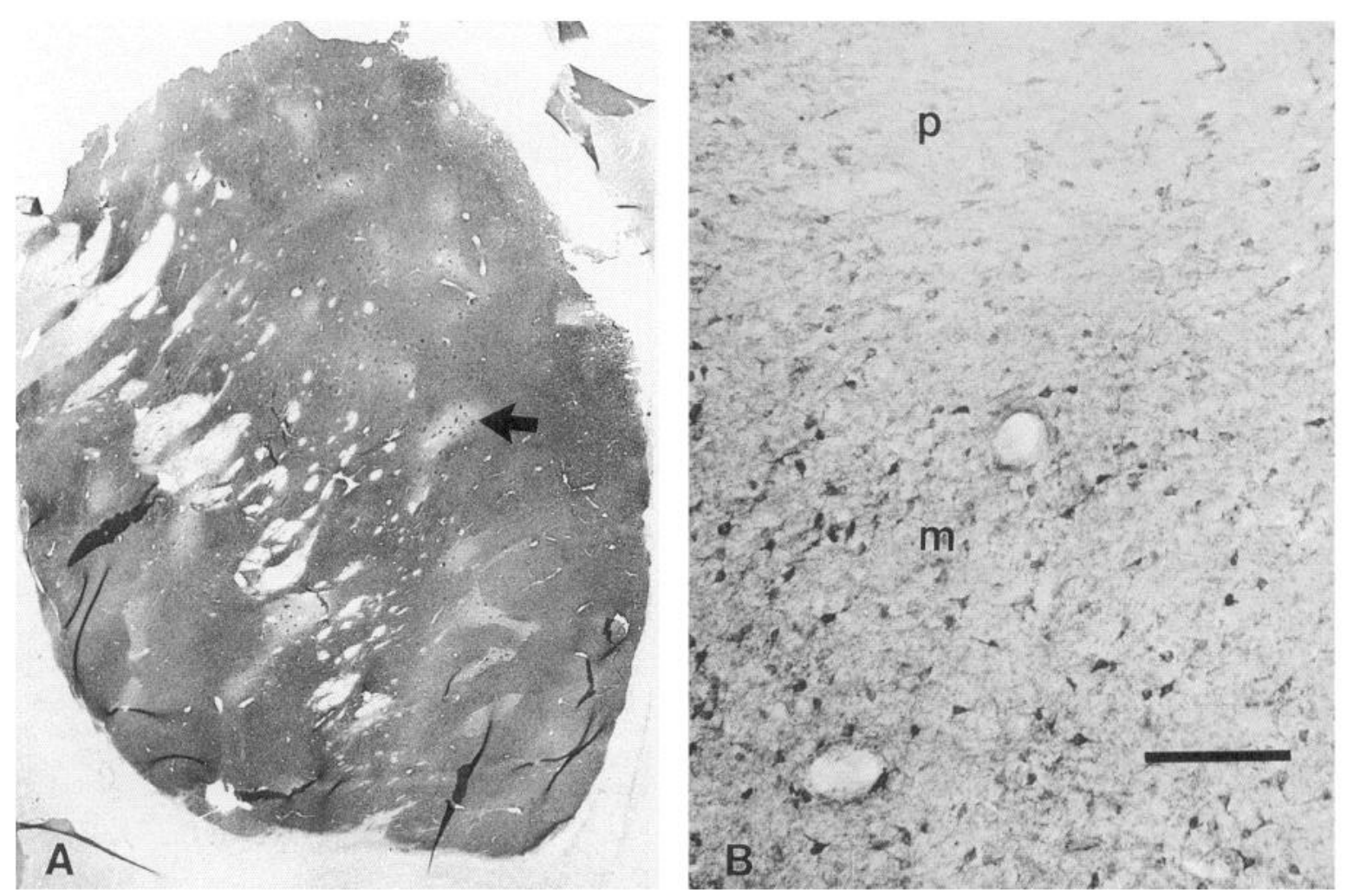

Figure 4. Calb immunocytochemical staining in human striatum. Low-power photomicrograph of the human striatum at the level of the nucleus accumbens $(A)$ demonstrates the heterogeneous distribution of Calb activity. Intense Calb activity is located in the matrix zone, with less activity in patch compartments (arrow). A photomicrograph $(B)$ of the border zone between the matrix $(m)$ and a patch $(p)$ compartment demonstrates that Calb-positive neurons and axon terminals are primarily confined to the matrix zone. Scale bar in $B, 400 \mu \mathrm{m}$.

mimic neuronal degeneration. Impregnation artifacts due to delayed postmortem handling of refrigeration and fixation were not observed in any of the cases in this study.

The failure of some neuronal subclasses in HD striatum to be impregnated should not be mistakenly interpreted as a reduction in these cellular elements. While only medium-sized spiny neurons were impregnated in sufficient numbers to permit adequate comparison to controls, the aspiny and sparsely spiny neurons that were observed showed no qualitative differences between HD and controls.

Neuronal vulnerability and resistance to the degenerative process in HD may depend upon inherent cytoarchitectonic relationships in which both the affected cell types and their regional distribution may be of importance. Spiny striatal neurons may be selectively involved because of their position within the neural network. Corticostriatal glutamatergic afferents may exacerbate neuronal excitability, already increased by an endogenous excitotoxin or trophic factors, and cause cell death.

One theory of cell death in HD suggests that an excitotoxin may excessively stimulate striatal neurons receiving glutamatergic corticostriatal projections (Olney, 1978; Whetsell and
Schwarcz, 1983; Schwarcz et al., 1984). The genetic defect in HD may allow an abnormal accumulation or production of an endogenous excitotoxin, which may act directly at NMDA receptor sites. The neurotoxin hypothesis has gained support with the demonstration that experimental excitotoxic striatal lesions using quinolinic acid (QA), an NMDA agonist, replicate almost precisely the neuropathological and neurochemical profile of HD (Beal et al., 1986). While there is some disagreement over these results (Boegman et al., 1987; Davies and Roberts, 1987), subsequent studies have confirmed the excitotoxic model of HD in acute and chronic QA lesions in both rodent and primate striatum (Beal et al., 1989a,b, 1991). Intact corticostriatal input enhances striatal QA toxicity, suggesting some synergism between QA and glutamate (Whetsell and Schwarcz, 1983). QA may act at both pre- and postsynaptic receptor sites, with presynaptic binding causing massive release of glutamate (Connick and Stone, 1988a,b). Dendritic spines receive the bulk of the synaptic corticostriatal input, which may explain the preferential damage of spiny striatal neurons.

It has been suggested that glutamate-releasing axons may, in themselves, regulate neuronal dendritic growth. In cell cultures,

Figure 3. Medium-sized spiny striatal neurons in severe grades (grades 3 and 4) of HD. Camera lucida drawings of typical spiny neurons are represented in grade $3(A$ and $B)$ and grade $4 \mathrm{HD}(C)$. Degenerative changes are the most frequent dysmorphic alterations observed in these grades. These neurons are characterized by marked spine loss, irregular focal swellings along dendrites, and acute recurving of the distal dendritic segment. Truncated dendritic arbors are most prominent in grade 4. D. Photomicrograph of a field of spiny neurons in the caudate nucleus in grade 3 HD. Photomontages of dendritic arbors in $E$ and $F$ represent those arbors identified by asterisks in $A$ and $B$, respectively. Scale bars: $A, 50 \mu$ m for $A-$ $C ; D, 50 \mu \mathrm{m}$. 

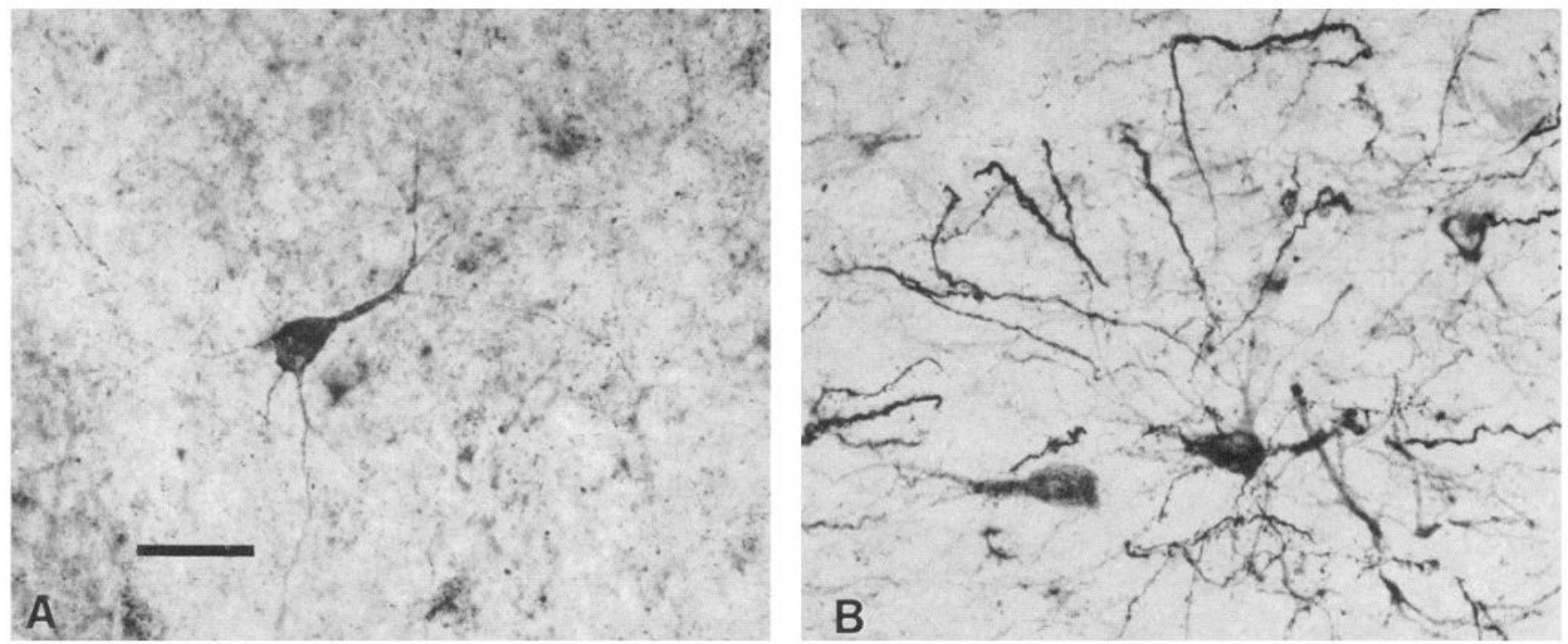

Figure 5. Calb immunocytochemical staining of striatal neurons in normal $(A)$ and $\operatorname{HD}(B)$ striatum. Although Calb activity delineated the entire neuron in the normal striatum, the greatest intensity of immunoreactivity was found within the cell soma and primary and secondary dendritic arbors. In contrast, there was a distal dendritic shift of immunoreactive Calb intensity in HD striatal neurons. The cell soma was strongly immunoreactive, with far less immunoreactivity in the primary and secondary dendrites. Distal arbors were intensely immunoreactive. Note recurving of the terminal segment of dendrites. Scale bar, $50 \mu \mathrm{m}$ for $A$ and $B$.

low concentrations of glutamate can act to induce neuronal sprouting (Koelle et al., 1986), while increasingly higher concentrations of glutamate can cause dendritic regression and subsequent neuronal degeneration (Choi et al., 1987; Mattson et al., 1988). This pattern of neuronal cell death preceded by proliferative changes in neurons is similar to what we have observed in the progression of cytopathologic changes in HD.

Human studies of temporal lobe epilepsy demonstrate that selective neuronal damage leads to a synaptic reorganization of neurons involving both dendritic and axonal elements (DeLorenzo and Glaser, 1981; Houser et al., 1990). Neuronal growth may be triggered by deafferentation (Morest, 1975). The pro- liferative alterations observed in HD may be an attempt at remodeling by the cell in order to reconstruct neuronal contacts lost early in the disease process.

Whether as a consequence of some initial neurotoxic insult to the striatum or the presence of a neurotrophic factor, the neuronal plasticity observed in the early stages of HD may play an important role in the death of spiny neurons in this disorder. If newly formed dendritic arbors and increased numbers of dendritic spines establish functional connections, they may facilitate neuronal excitability and exacerbate neuronal death. Neuronal proliferation, rather than degeneration, may thus be the harbinger of cell death in HD.
Figure 6. Calb-immunoreactive staining in normal $(A)$ and $\mathrm{HD}(B)$ caudate nucleus. The number of immunopositive neurons and amount of neuropil staining are significantly reduced in HD. Scale bar, $100 \mu \mathrm{m}$ for $A$ and $B$.
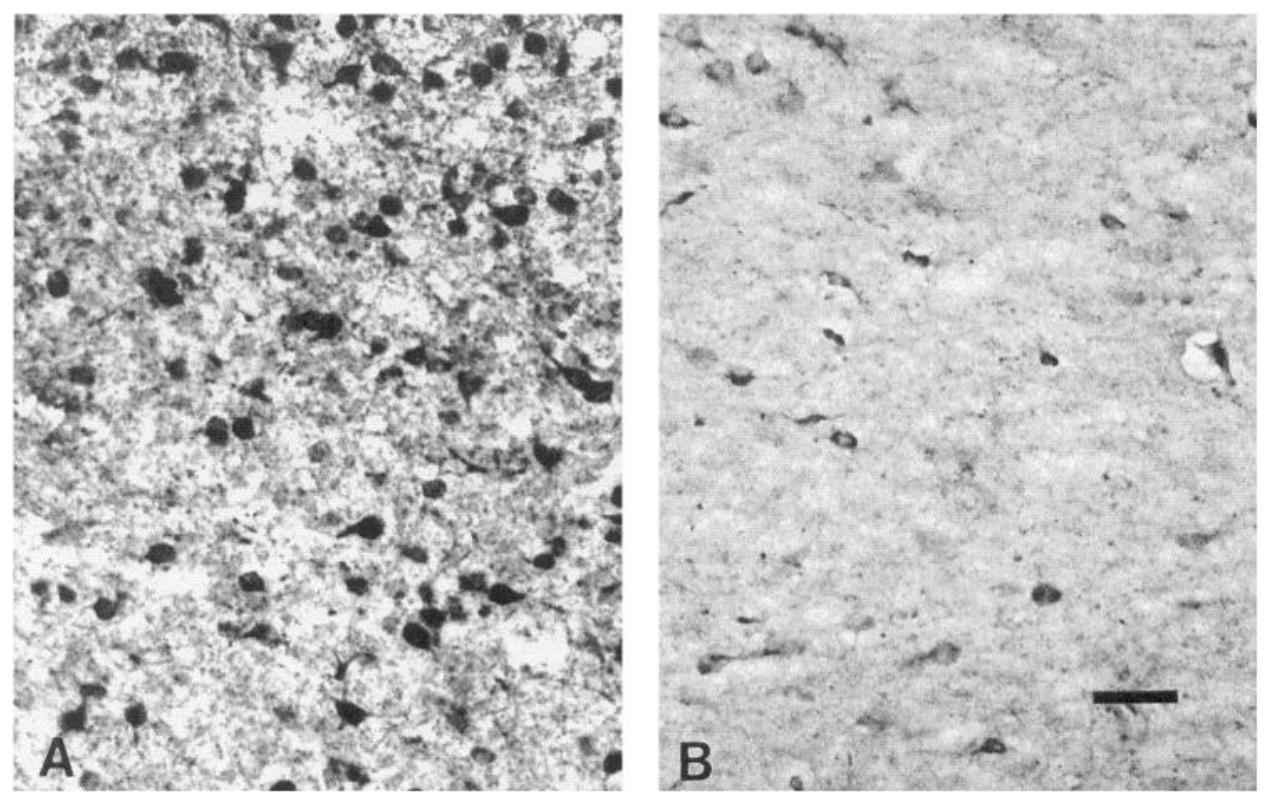


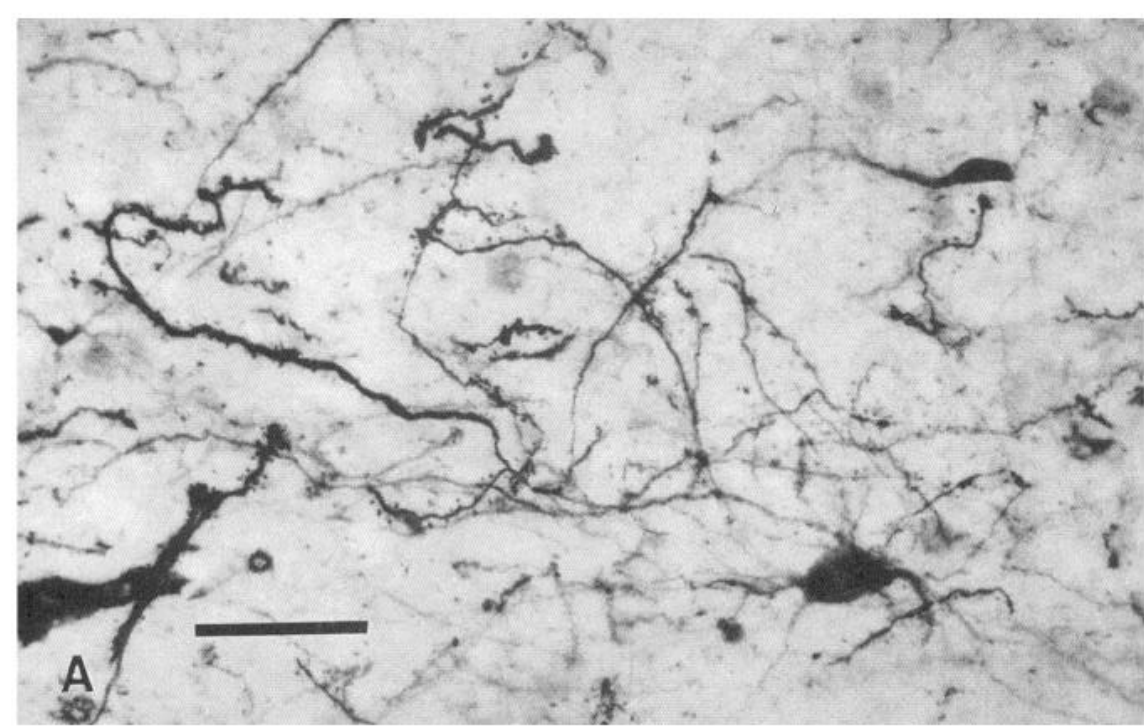

Figure 7. Calb-immunoreactive neuron in HD striatum. Dysmorphic alterations, as demonstrated in Golgi preparations, were present in most Calbpositive neurons in HD striatum. Note tortuous branching pattern, recurving distal arbors, distal dendritic branching and clubbing, and spine loss. Scale bar, $50 \mu \mathrm{m}$.
The gradient of Calb neuronal loss found in this study is consistent with the neuropathologic (Vonsattel et al., 1985), immunohistochemical (Ferrante et al., 1986, 1988; Seto-Ohshima et al., 1988; Goto et al., 1989), and biochemical (Beal et al., 1988) evidence, supporting the dorsoventral and mediolateral progression of cell death in HD striatum. The earliest and most extensive degenerative changes occur in the superior and medial aspect of the caudate nucleus.

Increased neuronal calcium is thought to play an important role in excitotoxic cell death, which, as already indicated, may be the basis for neuronal degeneration in HD (Collins, 1987; Choi, 1988; van den Pol, 1990). Calb, among other neurochemical substances, has the capacity to bind calcium and may function as a cellular calcium buffer (Heizmann, 1984; Stichel et al., 1987; Houser et al., 1990). It has been suggested that Calb neurons may be less vulnerable to the excitotoxic effects caused by increased intracytosolic calcium (Nitsch et al., 1989; Slotvier, 1989; Yamada et al., 1990). This does not appear to be the case in HD striatum. While Calb neurons may have increased calcium buffering capacity as compared with other striatal neurons, their death may be the consequence of a greater number of excitatory inputs to these neurons. Calb neurons could therefore have more intrinsic resistance to excitotoxic damage but nevertheless be particularly vulnerable due to their afferent inputs.

The immunocytochemical findings are remarkable in that they demonstrate Golgi-like alterations in a neurochemically distinct subpopulation of striatal neurons in HD. The dysmorphic changes in Calb-positive neurons are similar to those identified in section-Golgi preparations in the same cases. In addition to these morphologic abnormalities, there is a shift in the intensity of Calb immunoreactivity to distal dendritic arbors, an area associated with new growth. This distal dendritic shift of immunoreactivity is not a phenomenon that is unique to this disorder. It has previously been demonstrated in Alzheimer's disease (McKee et al., 1989). It may represent a form of neuronal plasticity in which increased intracellular metabolites are provided to those areas involved in the growth process. Developing dendritic membranes are rich in voltage-dependent calcium channels and may contain greater concentrations of calcium than elsewhere in the cell (Mayer and Westbrook, 1987). The redistribution of Calb within dendrites of spiny neurons in HD may therefore be related to calcium-dependent processes that occur as a result of neuronal plasticity. This concept has been suggested by Stichel et al. (1987) in describing the shift in neuronal Calb immunoreactivity in the developmental maturation of the visual cortex. Alternatively, increased synthesis of Calb may occur secondarily due to a cascade of events initiated by continued neuronal depolarization. Changes in the level of expression of neurochemicals and alterations in neuronal plasticity may result as a consequence of the activation of immediate early genes (IEG) (Sheng and Greenberg, 1990). NMDA receptor stimulation and calcium influx induce the expression of the protooncogenes c-jun and c-fos (Morgan and Curran, 1988; Cole et al., 1989; Szekely et al., 1989). These two IEG complexes, in turn, may activate other target genes and upregulate such substances as proenkephalin (Morris et al., 1988; Sonnenberg et al., 1989), somatostatin (Patel et al., 1989), cholecystokinin (Iadarola et al., 1986), and NGF (Gall and Isackson, 1989). The increased biosynthesis of Calb in spiny striatal neurons in HD may reflect a similar mechanism. Whether or not the pattern of immunocytochemical and morphological alterations observed in this study are present in other neurochemically distinct subpopulations of neurons within HD striatum needs to be determined.

\section{References}

Baimbridge KG, Miller JJ, Parkes CO (1982) Calcium-binding protein distribution in the rat. Brain Res 239:519-525.

Beal MF, Kowall NW, Ellison DW, Mazurek MF, Swartz KJ, Martin JB (1986) Replication of the neurochemical characteristics of Huntington's disease by quinolinic acid. Nature 321:168-171.

Beal MF, Ellison DW, Mazurek MF, Swartz KS, Malloy JR, Bird ED, Martin JB (1988) A detailed examination of substance $P$ in pathologically graded cases of Huntington's disease. J Neurol Sci 84:51-61.

Beal MF, Kowall NW, Ferrante RJ, Cipolloni PB (1989a) Quinolinic acid striatal lesions in primates as a model of Huntington's disease. Ann Neurol 26:137.

Beal MF, Kowall NW, Swartz KJ, Ferrante RJ, Martin JB (1989b) Differential sparing of somatostatin-neuropeptide $\mathrm{Y}$ and cholinergic neurons following striatal excitotoxin lesions. Synapse 3:38-47.

Beal MF, Ferrante RJ, Swartz KJ, Kowall NW (1991) Chronic quinolinic acid lesions in rats closely resemble Huntington's disease. J Neurosci 11:1649-1659. 
Besson MJ, Graybiel AM, Quinn B (1990) Co-expression of neuropeptides in the cat's striatum: an immunohistochemical study of substance $P$, dynorphin and enkephalin. Neuroscience 39:33-58.

Boegman RJ, Smith Y, Parent A (1987) Quinolinic acid does not spare striatal neuropeptide Y-immunoreactive neurons. Brain Res 415:178182.

Buell SJ, Coleman PD (1979) Dendritic growth in the aged human brain and failure of growth in senile dementia. Science 206:854-856.

Celio MR (1990) Calbindin D-28k and parvalbumin in the rat nervous system. Neuroscience 35:375-475.

Choi DW (1988) Glutamate neurotoxicity and diseases of the nervous system. Neuron 1:623-634.

Choi DW, Maulucc-Gedde MA, Kriegstein AR (1987) Glutamate neurotoxicity in cortical cell culture. J Neurosci 7:357-368.

Cole AJ, Saffen DW, Barahan JM, Worley PF (1989) Rapid increase of an immediate early gene messenger RNA in hippocampal neurons by synaptic NMDA receptor activation. Nature 340:474-476.

Collins RC (1987) Neurotoxins and the selective vulnerability in the brain. In: Neurotoxins and their pharmocological implications (Jenner $P$, ed), pp 1-17. New York: Raven.

Connick JH, Stone TW (1988a) Excitatory amino acid antagonists and endogenous aspartate and glutamate release from rat hippocampal slices. Br J Pharmacol 93:863-867.

Connick JH, Stone TW (1988b) Quinolinic acid effects on amino acid release from the rat cerebral cortex in vitro and in vivo. Br J Pharmacol 93:868-876.

Davies SW, Roberts PJ (1987) No evidence for preservation of somatostatin containing neurons after intrastriatal injections of quinolinic acid. Nature 327:326-329.

Dawbarn D, DeQuidt ME, Emson PC (1985) Survival of basal ganglia neuropeptide $Y$-somatostatin neurones in Huntington's disease. Brain Res 340:251-261.

DeLorenzo RJ, Glaser GH (1981) Neuropathologic changes and neuronal plasticity in temporal lobe-limbic epilepsy. Neurology 31:114.

DiFiglia M, Christakos S, Aronin N (1989) Ultrastructural localization of immunoreactive calbindin-D 28k in the rat and monkey basal ganglia, including subcellular distribution with colloidal gold labeling. J Comp Neurol 279:653-665.

Fallon JH (1987) Growth factors in the basal ganglia. In: Basal ganglia II: structure and function-current concepts (Carpenter MB, Jayaraman A, eds), pp 247-260. New York: Plenum.

Ferrante RJ, Kowall NW, Beal MF, Richardson EP Jr, Bird ED, Martin JB (1985) Selective sparing of a class of striatal neurons in Huntington's disease. Science 230:561-563.

Ferrante RJ, Kowall NW, Beal MF, Richardson EP Jr, Bird ED, Martin JB (1986) Topography of enkephalin, substance $P$, and acetylcholinesterase staining in Huntington's disease striatum. Neurosci Lett 71:283-288.

Ferrante RJ, Kowall NW, Beal MF, Martin JB, Bird ED, Richardson EP Jr (1987a) Morphologic and histochemical characteristics of a spared subset of striatal neurons in Huntington's disease. J Neuropathol Exp Neurol 46:12-27.

Ferrante RJ, Beal MF, Kowall NW, Richardson EP Jr, Martin JB (1987b) Sparing of acetylcholinesterase-containing striatal neurons in Huntington's disease. Brain Res 411:162-166.

Ferrante RJ, Kowall NW, Hersh LB, Bruce G, Richardson EP Jr (1987c) Co-localization of cholineacetyltransferase- and acetylcholinesterasecontaining neurons in Huntington's disease. Soc Neurosci Abstr 13: 1030.

Ferrante RJ, Kowall NW, Martin JB, Richardson EP Jr (1987d) Substance $P$-containing striatal neurons in Huntington's disease. J Neuropathol Exp Neurol 46:375.

Ferrante RJ, Kowall NW, Gerfen CR, Richardson EP Jr (1988) Immunocytochemical localization of calcium-binding protein in normal and Huntington's disease striatum. J Neuropathol Exp Neurol 47: 352

Fox CA, Andrade AN, Hillman DE, Schwyn RC (1971) The spiny neurons in the primate striatum: a Golgi and electron microscopic study. J Hirnforsch 13:181-201.

Gabbott PL, Somogyi J (1984) The 'single' section Golgi-impregnation procedure: methodological description. J Neurosci Methods 11:221230.

Gall CM, Isackson PJ (1989) Limbic seizures increase neuronal production of messenger RNA for nerve growth factor. Science 245:758761

Gallyas F, Gores T, Merchenthaler I (1982) High grade intensification of the end product of diaminobenzidine reaction demonstrating peroxidase activity. J Histochem Cytochem 30:183-184.

Gerfen CR, Baimbridge KG, Miller JJ (1985) The neostriatal mosaic: compartmental distribution of calcium-binding protein and parvalbumin in the basal ganglia of the rat and monkey. Proc Natl Acad Sci USA 82:8780-8784.

Goto S, Hirano A, Rojas-Corona RR (1989) An immunohistochemical investigation of the human neostriatum in Huntington's disease. Ann Neurol 25:298-304.

Graveland GA, Williams RS, DiFiglia MA (1985a) A Golgi study of the human neostriatum: neurons and afferent fibers. J Comp Neurol 234:317-333.

Graveland GA, Williams RS, DiFiglia MA (1985b) Evidence for degenerative and regenerative changes in neostriatal spiny neurons in Huntington's disease. Science 227:770-773

Graybiel AM, Ragsdale CW (1983) Biochemical anatomy of the striatum. In: Chemical anatomy (Emson PC, ed), pp 427-504. New York: Raven.

Heizmann CW (1984) Parvalbumin, an intracellular calcium-binding protein, distribution properties and possible roles in mammalian cells. Experientia 40:910-921.

Houser CR, Miyashiro JE, Swartz BE, Walsh GO, Rich JR, DelgadoEscueta AV (1990) Altered patterns of dynorphin immunoreactivity suggest mossy fiber reorganization in human hippocampal epilepsy. J Neurosci 10:267-282.

Iadarola MJ, Shin C, McNamara JO, Yang H-YT (1986) Changes in dynorphin, enkephalin and cholecystokinin content of hippocampus and substantia nigra after amygdala kindling. Brain Res 365:185-191.

I7.7o PN, Graybiel AM, Bolam JP (1987) Characterization of substance $P$ - and [met]enkephalin-immunoreactive neurons in the caudate nucleus of the cat and ferret by a single section Golgi procedure. Neuroscience 20:577-587.

Kiyama H, Seto-Ohshima A, Emson PC (1990) Calbindin D28k as a marker for the degeneration of the striatonigral pathway in Huntington's disease. Brain Res 525:209-214.

Koelle GB, Sanville UJ, Thampi NS, Wall SJ (1986) L-Glutamic acid a neurotrophic factor for maintenance of acetylcholinesterase and butyrylcholinesterase in the preganglionically denervated superior cervical ganglion of the cat. Proc Natl Acad Sci USA 83:2751-2754.

Kowall NW, Ferrante RJ, Martin JB (1987a) Patterns of cell loss in Huntington's disease. Trends Neurosci 10:24-29.

Kowall NW, Ferrante RJ, Beal MF, Richardson EP Jr, Sofreniew M, Cuello AC, Martin JB (1987b) Neuropeptide Y, somatostatin, and NADPH diaphorase in human striatum: a combined immunocytochemical and enzyme histochemical study. Neuroscience 20:817.

Levey AI, Wainer BH, Mufson EJ, Mesulam M-M (1983) Colocalization of acetylcholinesterase and choline acetyltransferase in the rat cerebrum. Neuroscience 9:9-22.

Martin JB, Gusella JF (1986) Huntington's disease: pathogenesis and management. N Engl J Med 315:1267-1276.

Mattson MP, Dou P, Kater SB (1988) Outgrowth-regulating actions of glutamate in isolated hippocampal pyramidal neurons. J Neurosci 8:2087-2100.

Mayer ML, Westbrook GL (1987) Cellular mechanisms underlying excitotoxicity. Trends Neurosci 10:59-61.

McKee AM, Kowall NW, Kosik KS (1989) Microtubular reorganization and dendritic growth response in Alzheimer's disease. Ann Neurol 26:652-659.

Morest DK (1969) The differentiation of cerebral dendrites: a study of the post-migratory neuroblast in the medial nucleus of the trapezoid body. Z Anat Entwicklunggesch 128:271-289.

Morest DK (1975) Local circuit neurons in the medial geniculate body of the cat. In: Local circuit neurons (Rakic P, ed), Neurosciences research program bulletin, Vol 13, pp 367-377. Cambridge, MA: MIT.

Morest DK, Morest RR (1966) Perfusion fixation of the brain with chrome-osmium solutions for the rapid Golgi method. Am J Anat 118:811-832.

Morgan JI, Curran T (1988) Calcium as a mediator of the immediateearly gene cascade in neurons. Cell Calcium 9:303-311.

Morris BJ, Feasey KJ, ten Bruggencate G, Herz A, Hollt V (1988) Electrical stimulation in vivo increases the expression of proenkephalin mRNA and decreases the expression of prodynorphin mRNA in the rat hippocampal granule cells. Proc Natl Acad Sci USA 85:32263230

Nitsch C, Scotti A, Sommacal A, Kalt G (1989) GABAergic hippo- 
campal neurons resistant to ischemia induced ncuronal death contain $\mathrm{Ca}^{2+}$ binding protein parvalbumin. Neurosci Lett 105:263-268.

Olney JW (1978) Neurotoxicity of excitatory amino acids. In: Kainic acid as a tool in neurobiology (Olney JW, McGeer RL, eds), pp 95122. New York: Raven.

Parent A, Csonka C, Etienne P (1984) The occurrence of large acetylcholinesterase-containing neurons in human neostriatum as disclosed in normal and Alzheimer's diseased brains. Brain Res 291: 154-158.

Patel SC, Papachristou DN, Patel YC (1989) Quinolinic acid increases somatostatin mRNA and peptide levels in cultured rat cortical neurons. Soc Neurosci Abstr 15:935.

Reiner A, Albin RL, Anderson KD, D'Amato CJ, Penney JB, Young AB (1988) Differential loss of striatal projection neurons in Huntington's disease. Proc Natl Acad Sci USA 85:5733-5737.

Ribak CE, Vaughn JE, Roberts E (1979) The GABA neurons and their axon terminals in the rat corpus striatum as demonstrated by GAD immunocytochemistry. J Comp Neurol 187:261-284.

Schwarcz R, Foster AC, French ED, Whetsell WO, Kohler C (1984) Excitotoxic models for neurodegenerative disorders. Life Sci 35:1932.

Seto-Ohshima A, Emson PC, Lawson E, Mountjoy CQ, Carrasco LH (1988) Loss of matrix calcium-binding protein-containing neurons in Huntington's disease. Lancet 1252-1255.

Sheng M, Greenberg ME (1990) The regulation and function of c-fos and other immediate early genes in the nervous system. Neuron 4: 473-485.

Slotvier RS (1989) Calcium-binding protein (calbindin D-28k) and parvalbumin immunocytochemistry: localization in the rat hippocampus with specific reference to the selective vulnerability of hippocampal neurons to seizure activity. J Comp Neurol 280:182-196. Sonnenberg JL, Rauscher FJ, Morgan JI, Curran T (1989) Regulation of proenkephalin by Fos and Jun. Science 246:1622-1625.
Stichel CC, Singer W, Heizmann CW, Norman AW (1987) Immunohistochemical localization of calcium-binding protein and calbindin-D 28k, in the adult and developing visual cortex of cats: a light and electron microscopic study. J Comp Neurol 262:563-577.

Szekely AM, Barbaccia ML, Alho H, Costa E (1989) In primary cultures of cerebellar granule cells the activation of $N$-methyl-D-aspartate-sensitive glutamate receptors induces c-fos mRNA expression. Mol Pharmacol 35:401-408.

Takagi H, Mizuta H, Matsuda T, Inagaki S, Tateishi K, Hamaoka T (1984) The occurrence of cholecystokinin-like immunoreactive neurons in the rat neostriatum: light and electron microscopic analysis. Brain Res 309:346.

Theriault E, Marshall PE, Landis DMD (1987) Morphology of neurons containing VIP-like immunoreactivity. J Comp Neurol 256:1-13.

van den Pol AN, Wuarin J-P, Dudck FW (1990) Glutamate, the dominant excitatory transmitter in neuroendocrine regulation. Science 250:1276-1278.

Vonsattel J-P, Meyers RH, Stevens TJ, Ferrante RJ, Bird ED, Richardson EP Jr (1985) Neuropathological classification of Huntington's disease. J Neuropathol Exp Neurol 44:559-577.

Whetsell WO, Schwarcz R (1983) Mechanisms of excitotoxins examined in organotypic cultures of rat central nervous system. In: Excitotoxins (Fuxe K, Roberts P, Schwarcz R, eds), pp 207-219. New York: Plenum.

Williams RS, Lott IT, Ferrante RJ, Caviness VS (1977) The cellular pathology of neuronal ceroid-lipofuscinosis. Arch Neurol 34:298305 .

Williams RS, Ferrante RJ, Caviness VS (1978) The Golgi rapid method in clinical neuropathology: the morphologic consequences of suboptimal fixation. J Neuropathol Exp Neurol 38:13-33.

Yamada T, McGeer PL, Baimbridge KG, McGeer EG (1990) Relative sparing in Parkinson's disease of substantia nigra dopamine neurons containing calbindin-D28k. Brain Res 526:303-307. 